$53^{\text {rd }}$ AIAA Structures, structural dynamics and materials conference, SDM 2012

Chapter DOI: 10.2514/6.2012-1733 | Publication Date: 23 April 2012

Publishers website: http://arc.aiaa.org/doi/abs/10.2514/6.2012-1733

\title{
On the determination of fatigue properties of Ti6Al4V produced by selective laser melting
}

\author{
B. Van Hooreweder ${ }^{1}$, R. Boonen ${ }^{2}$, D. Moens ${ }^{3}$, J.P. Kruth ${ }^{3}$, P. Sas ${ }^{3}$ \\ KU Leuven, Department of Mechanical Engineering, B-3001 Leuven, Belgium
}

\begin{abstract}
This paper provides new insights into the fatigue properties of Selective Laser Molten components made from Ti6AI4V powder particles. The SLM-process parameters are optimized and high quality SLM-parts with a relative density of $99.7 \%$ are produced. Uniaxial fatigue experiments are then performed on notched and unnotched specimens and the endurance limits are determined using the staircase method and the theory of Dixon and Mood. The presented results indicate inferior fatigue strength in comparison with conventionally produced components from Ti6Al4V. Microstructural analysis shows that this is mainly due to the anisotropy in the microstructure and the weak grain boundaries between epitaxial grains. However, the failure mechanism is consistant leading to low statistical scatter in the fatigue data. Furthermore, the critical volume method and the critical distance theory have proven to be accurate and efficient design tools to account for the notch-effect in SLM-Ti6Al4V.
\end{abstract}

\section{Nomenclature}

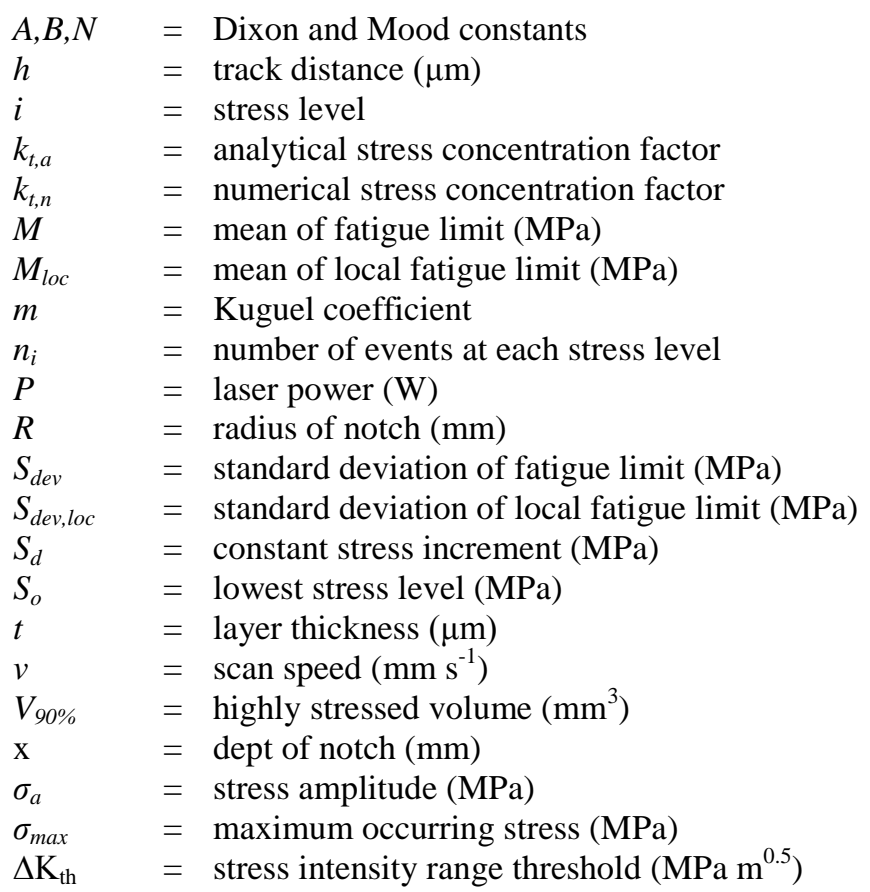

${ }^{1}$ PhD student, Dept. of Mechanical Engineering, KU Leuven, Celestijnenlaan 300b, B-3001 Leuven, Belgium, Brecht.vanhooreweder@mech.kuleuven.be.

${ }^{2}$ Senior research engineer, Dept. of Mechanical Engineering, KU Leuven.

${ }^{3}$ Professor, Dept. of Mechanical Engineering, KU Leuven.

American Institute of Aeronautics and Astronautics 


\section{Introduction}

$\mathrm{T}$ HE main goal of this research is to describe and analyze the fatigue behavior of Ti6Al4V produced by Selective Laser Melting (SLM). Additive manufacturing techniques like SLM make use of laser radiation to produce functional parts from powder particles. Layers of these particles are spread and laser radiation is used to fully melt the powdered material in a protective argon atmosphere. Molten and resolidified material forms parts while unmolten material remains in place to support the structure. ${ }^{1-3}$ This layer-wise production technique offers some advantages over conventional manufacturing techniques such as high geometrical freedom, short design and manufacturing cycle time, customized components and a wide material range. Furthermore, the un-molten powder can be reused, leading to a highly efficient material usage which is beneficial for components made from expensive materials like Ti-alloys. Layer-wise production techniques have evolved rapidly in the last 10 years and SLM has changed from a rapid prototyping to a rapid manufacturing technique. Consequently, the static and dynamic material properties of the resulting parts must be sufficient to meet in service loading and operational requirements. It is well known that the mechanical properties of SLM-parts can differ substantially from those of the same parts produced by conventional techniques. This is mainly due to the large quantity of process parameters such as layer thickness, energy density, scan strategy, scan speed, preheating temperature, etc. that have a strong influence on the microstructure and the mechanical properties of the final product. It is clear however, that one can only fully benefit from the advantages of SLM when the mechanical behavior of the final products equals that of the conventionally produced components in the same material.

During the last years, many research efforts were made to optimize the SLM-process in order to improve the quality and mechanical performance of the resulting products. At present, material properties like tensile strength, yield strength, hardness and impact toughness are well understood and published. ${ }^{4,5}$ When the correct process parameters are applied, the static material behavior of SLM-parts approximates the material behavior acquired by means of traditional production processes. The remaining material imperfections due to the SLM process have limited effect on these static material properties since the static material behavior is depending on the average behavior of a large number of elements.

On the other hand, very little has been reported in literature on the properties of SLM-Ti6Al4V when subjected to fluctuating loading conditions. The knowledge of these properties is limited and accurate fatigue life predictions are therefore not possible. Moreover, conventional safety factors or ad hoc design rules are likely to result in unconservative and unsafe designs. In contrast to static failure, fatigue failure arises from failure of the weakest element. Therefore, microstructural imperfections due to the SLM process are likely to have a large influence on the fatigue crack initiation and propagation phase.

In the present work, a first attempt has been made to address this by studying the fatigue behavior of notched and unnotched specimens made from SLM-Ti6Al4V. At first, the scanning parameters are altered to optimize the density of the test specimens and to minimize the statistical scatter in the fatigue results. A high material density ensures fewer pores in the material leading to superior fatigue resistance. Secondly, fatigue data is generated using uniaxial fatigue experiments with constant amplitude loading and fixed test frequency. The endurance limit is determined using the staircase method and the Dixon and Mood principle. Finally, the highly stressed volume method and the critical distance theory are successfully applied and validated for fatigue life calculations of notched SLM-Ti6Al4V specimens.

\section{Materials}

The $(\alpha-\beta)$ Ti6Al4V alloy which is used is this research represents more than $50 \%$ of the worldwide production of titanium. Because of its corrosion resistance, high specific strength, stiffness and fabricability, it is the most commonly used titanium alloy. A variety of applications where mechanical components of Selective Laser Molten Ti6Al4V are used under complex cyclic loading conditions can be found in the automotive, aerospace and biomedical industry. ${ }^{6-9}$

\section{A. Microstructure and material density}

The microstructure of the SLM-Ti6Al4V products differs substantially from the microstructure of vacuum arc remelted (VAR) standard oxygen mill annealed Ti6Al4V as indicated in Figure 1. The globular microstructure of the reference material resulting from a slow cooling process is shown in Figure 1A. During SLM on the other hand, high temperature gradients occur due to laser interaction, leading to a fine acicular $\alpha^{\prime}$-martensite phase with sharp needles ${ }^{10}$ as indicated in Figure 1B. Furthermore, epitaxial grain growth can be noticed on the sides of the test specimens (Figure 1C), indicating vertical growth through the layers of the specimens in the direction of heat removal. ${ }^{10}$ This clear difference in microstructure can have a major impact on the fatigue properties of the material. 
Another important parameter is the material density. It is generally accepted that a high density ensures fewer pores in the material leading to an improved resistance against crack initiation and crack growth. ${ }^{11}$ A low density is characterized by many pores and inferior material properties. Moreover, the pores in the material often dominate the failure mechanisms, making it very difficult to predict or calculate the mechanical material behavior. Figure 1D shows an example of an SLM-Ti product with a density of only $97.06 \%$ due to suboptimal scanning parameters. It is clear that these pores act as microscopic stress raisers which are associated to stress concentration factors in the range of 5-12. Not only does this facilitate the initiation of fatigue cracks, also cracks can propagate more rapidly through the material.
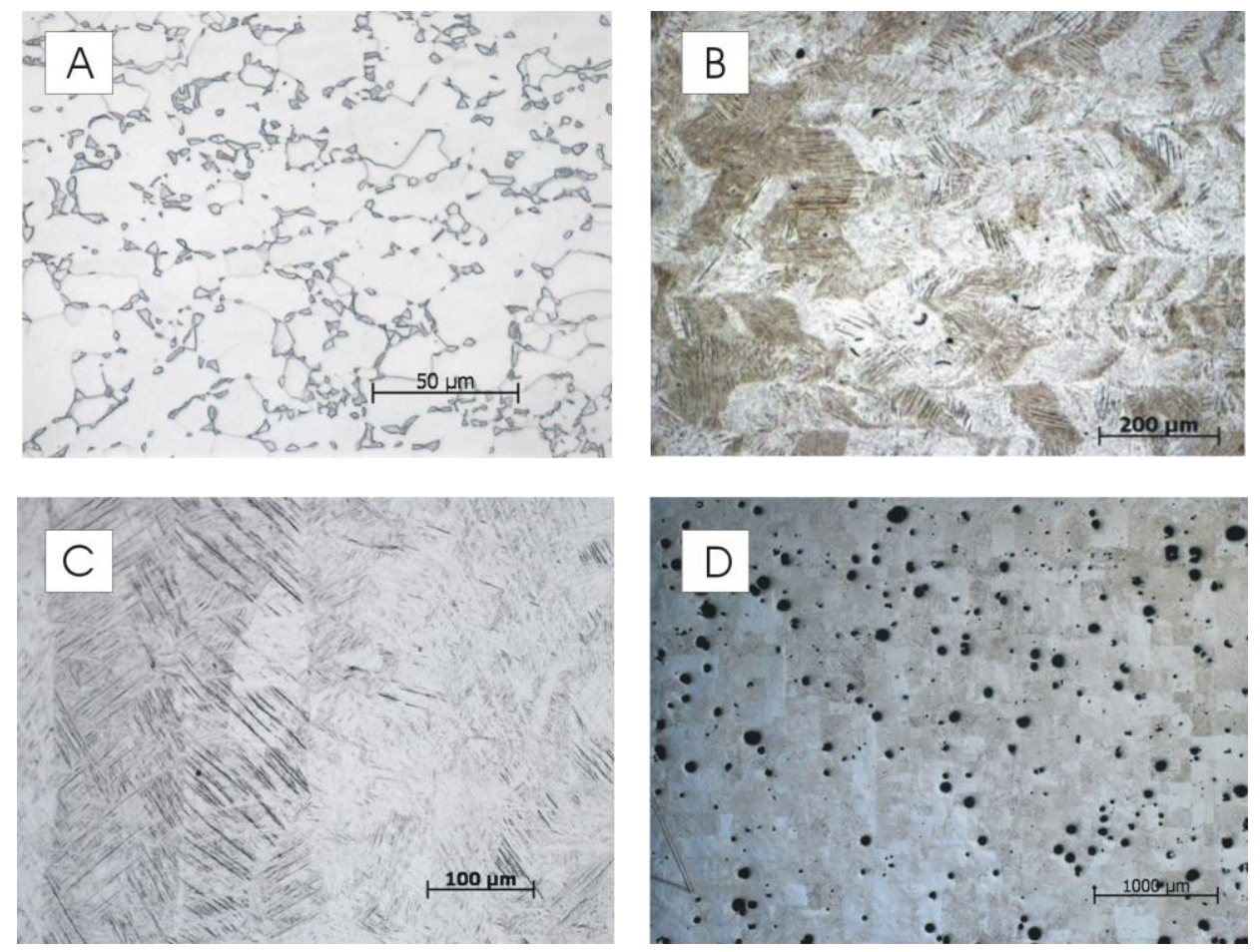

Figure 1. Micrographs of Ti6AI4V: VAR-Ti standard oxygen mill annealed (A), Top view of SLM-Ti (B), Side view of SLM-Ti (C), SLM-Ti with low density (D).

To optimize the production time and the density of the SLM test specimens that were used for the fatigue experiments, the in-house SLM machine ${ }^{12}$ was used to produce different cubical $\left(5 \times 5 \times 5 \mathrm{~mm}^{3}\right)$ blocks using different values for the laser power $\mathrm{P}(100,200,250 \mathrm{~W})$, scan speed $\mathrm{v}\left(63-1600 \mathrm{~mm} \mathrm{~s}^{-1}\right)$, track distance $\mathrm{h}(53-145 \mu \mathrm{m})$ and layer thickness $\mathrm{t}(30,60,90 \mu \mathrm{m})$ while maintaining the same energy density E. This parameter gives an indication of the energy supply during SLM and can be calculated using the previous parameters, $\mathrm{E}=\mathrm{P} / \mathrm{vht}$ in $\mathrm{J} \mathrm{mm}^{-3}$. A bidirectional scanning strategy was used for all the specimens. After scanning the contour, the first layer is scanned in zigzag and each successive layer is rotated by $90^{\circ}$ as indicated in Figure 2 . The relative density of the different blocks was measured using the Archimedes principle leading to a maximal value of $99.7 \%$ and a set of optimal scan parameters as indicated in Table 1. The relative density of the reference titanium was determined using the same principle leading to a value of $99,68 \%$. Hence, the material density of the SLM parts equals the density of the VAR material. This will not only drastically improve the fatigue properties of the SLM-parts, it also eliminates the pores as driving force for fatigue failure.

Table 1. Optimal scanning parameters for SLM-Ti6Al4V.

\begin{tabular}{cccc}
$\begin{array}{c}\text { Laser Power } \\
\mathrm{P}[\mathrm{W}]\end{array}$ & $\begin{array}{c}\text { Scan speed } \\
\mathrm{v}\left[\mathrm{mm} \mathrm{s}^{-1}\right]\end{array}$ & $\begin{array}{c}\text { Track distance } \\
\mathrm{h}[\mu \mathrm{m}]\end{array}$ & $\begin{array}{c}\text { Layer thickness } \\
\mathrm{t}[\mu \mathrm{m}]\end{array}$ \\
\hline 250 & 1600 & 60 & 30 \\
\hline
\end{tabular}




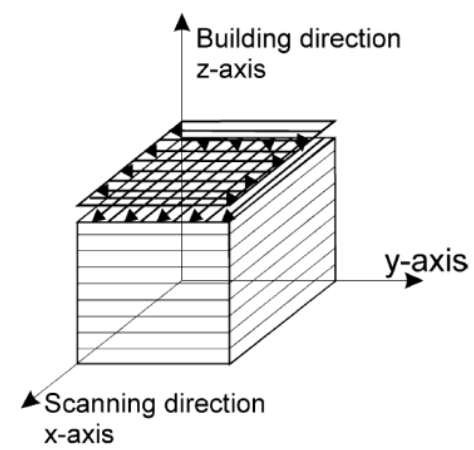

Figure 2. Bidirectional scanning strategy.

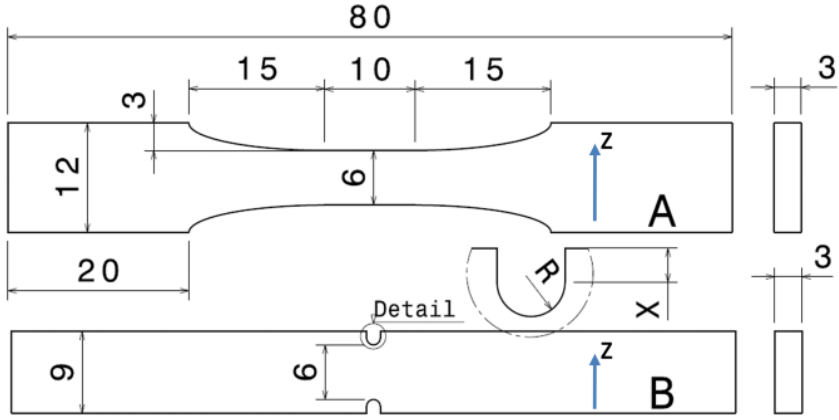

Figure 3. Fatigue test specimen geometry (in mm) unnotched (A) and notched (B).

\section{B. Specimen preparation}

The geometry of the notched and the unnotched fatigue specimens is shown in Figure 3. Multiple oversized specimens were build up layer by layer using the in-house SLM machine, the optimal scanning parameters, the bidirectional scanning strategy and building direction (z) as illustrated in Figure 3. After this, Electrical Discharge Machining (EDM) was used to remove the excess of material and to machine the notch. The EDM-process was executed in deionised water through seven consecutive gradually finer steps leading to a surface roughness (Ra) of $0.85 \mu \mathrm{m}$. Three different geometries were created with the same nominal cross section of $18 \mathrm{~mm}^{2}$. The unnotched specimens were manufactured with an elliptical transition instead of a circular one in order to reduce the influence of the so called stair effect. The stair effect can be defined as the inability to produce a continuous radius due to the layer-wise production technique. Tensile tests on standard specimen geometries produced with SLM have shown than the stress concentration caused by this effect is significantly lower when using an elliptical curve.

Equation 1 was then used to design specimen geometries with stress concentration factors ${ }^{13}$ of 1.75 and 2.5 as indicated in Table 2. Light microscopy was applied to verify the notch radius (R) and notch depth (x) for all specimens. The measured values $\left(\mathrm{R}_{\mathrm{m}}, \mathrm{x}_{\mathrm{m}}\right)$ show very little variation which is crucial to minimize the statistical scatter on the fatigue properties.

$$
k_{t, a}=1+\frac{1}{\sqrt{0.22 \frac{R}{x}+1.7 \frac{R}{b}\left(1+2 \frac{R}{b}\right)^{2}}}
$$

Table 2. Geometry of the notched specimens

\begin{tabular}{lll}
\hline & $\mathrm{k}_{\mathrm{t}, \mathrm{a}}=1.75$ & $\mathrm{k}_{\mathrm{t}, \mathrm{a}}=2.5$ \\
\hline $\mathrm{R}[\mathrm{mm}]$ & 2 & 0.75 \\
$\mathrm{R}_{\mathrm{m}}[\mathrm{mm}]$ & $2.0028 \pm 0.0044$ & $0.7492 \pm 0.0033$ \\
$\mathrm{x}[\mathrm{mm}]$ & 0 & 0.75 \\
$\mathrm{x}_{\mathrm{m}}[\mathrm{mm}]$ & 0 & $0.7509 \pm 0.0025$ \\
\hline
\end{tabular}

The SLM process is characterized by high temperature gradients $\left(10^{-6} \mathrm{~K} \mathrm{~s}^{-1}\right)$ and short interaction times $(\mathrm{ms}){ }^{1}$ The radiated material will swell due to the localized heat and the surrounding material will prevent this, causing non-linear compression of the radiated material. After solidification, this material will cool down and shrink leading to residual tensile stress at the surface of the SLM-part. Since these residual tensile stresses have a negative effect on the fatigue limit, all the fatigue specimens were heat treated for four hours at $650^{\circ} \mathrm{C}$ in a protective argon atmosphere.

Table 3. Tensile test results of as build and heat treated SLM-Ti6Al4V

\begin{tabular}{ccccc}
\hline & $\mathrm{E}[\mathrm{GPa}]$ & $\sigma_{\mathrm{y}}[\mathrm{MPa}]$ & $\sigma_{\mathrm{UTS}}[\mathrm{MPa}]$ & $\mathrm{A}[\%]$ \\
\hline SLM - Ti6Al4V & $109 \pm 3$ & $1115 \pm 13$ & $1271 \pm 8$ & $7.3 \pm 1.3$ \\
+ heat treatment & $114 \pm 1$ & $1124 \pm 7$ & $1170 \pm 6$ & $10.1 \pm 1.4$ \\
\hline
\end{tabular}

Tensile tests were performed according to ASTM E8M on as build and stress relieved specimens. Since residual stresses are in equilibrium and the tensile properties depend on the average material behavior of the cross sectional area, only little effect of the heat treatment is expected. The results of the tensile tests indicate that the heat treatment caused a change in microstructure leading to reduced ultimate tensile strength and improved ductility as shown in Table 3. Consequently, there are two benefits linked to the heat treatment: the relief of residual tensile stress in the outer material layers (1) and more ductile material behavior which allows the material to better resist distortion (2). 


\section{Method}

Fatigue crack initiation is most likely to start at places with high local stress amplitudes e.g. in the vicinity of stress raisers or notches. Unfortunately, macroscopic notches are always present in real life applications, often in the form of grooves, holes, keyways and fillets. It is generally agreed that the use of the theoretical stress concentration factor $\left(\mathrm{k}_{\mathrm{t}}\right)$ yields non-conservative results for fatigue data of ductile materials or when sharp notches are present. In these cases, the fatigue notch factor $\left(\mathrm{k}_{\mathrm{f}}<\mathrm{k}_{\mathrm{t}}\right)$ is used. Over the last years, many methods were developed to calculate $\mathrm{k}_{\mathrm{f}}$ based on statistics, crack growth or reversed yielding. ${ }^{13-16}$ However, none of these methods is suitable for all fatigue cases, often leading to the use of empirical formulas to cope with the influence of stress raisers on the fatigue life of different materials. In this study, the endurance limit is determined using the staircase method and the Dixon and Mood principle. Furthermore, the highly stressed volume method and the critical distance theory are successfully applied and validated for the fatigue life prediction of notched components in SLM-Ti6Al4V. The following subsections present a brief description of these methods.

\section{A. Determination of the endurance limit}

The endurance limit of the SLM parts was determined using constant amplitude cyclic uniaxial loading $(\mathrm{R}=0)$ at $75 \mathrm{~Hz}$ in a controlled environment. During the fatigue experiments, the material temperature near the notch remained constant over time. This was confirmed by the hysteresis plots between force and displacement which were represented by straight lines, indicating that no energy was dissipated during the cyclic loading.

In the finite fatigue region, seven unnotched specimens were tested at different stress levels. In the infinite fatigue region $\left(2 \times 10^{5}-10^{7}\right.$ cycles $)$ the staircase method, also known as the up-and-down method, was used to determine the endurance limit for the notched and the unnotched specimens. This method was originally developed by Dixon and Mood in 1948 for explosives research and is now a commonly used method for determining statistical characteristics of the fatigue strength based on the maximum-likelihood estimation principle. ${ }^{17-20}$ The primary advantage of this method is that it automatically concentrates testing near the mean. According to Dixon and Mood, 30 to $40 \%$ fewer tests are required with respect to ordinary methods of testing groups of equal size at preassigned stresses.

To start, the fatigue endurance limit is estimated using available fatigue data in literature ${ }^{21,22}$ and the first test is executed. If the specimen fails prior to $10^{7}$ cycles, the following experiment is performed at lower stress amplitude. If the specimen survives $10^{7}$ cycles, the test is stopped and the next experiment is run at higher stress amplitude. By doing so, each experiment is dependent on the result of the previous test. Assuming the variation of the applied fatigue limit to be normally distributed and using a fixed interval between the stress levels, the mean (M) and standard deviation $\left(\mathrm{S}_{\mathrm{dev}}\right)$ of the fatigue limit are estimated using the following equations:

$$
\begin{gathered}
M=S_{0}+S_{d}\left(\frac{A}{N} \pm \frac{1}{2}\right) \\
S_{d e v}=1.620 \times S_{d}\left(\frac{B N-A^{2}}{N^{2}}+0.029\right) \quad \text { if } \frac{B N-A^{2}}{N^{2}} \geq 0.3 \\
S_{d e v}=0.530 \times S_{d} \quad \text { if } \quad \frac{B N-A^{2}}{N^{2}}<0.3 \\
\text { with } A=\sum_{i=0}^{i_{\max }} i \times n_{i}, B=\sum_{i=0}^{i_{\max }} i^{2} \times n_{i}, N=\sum_{i=0}^{i_{\max }} n_{i}
\end{gathered}
$$

For calculating the mean, the plus sign is used if the more frequent event is survival and the minus sign is used if the more frequent event is failure. Furthermore, ' $i$ ' represents the stress level, where $i=0$ for the lowest stress level ' $\mathrm{S}_{\mathrm{o}}$ ', ' $\mathrm{n}_{\mathrm{i}}$ ' indicates the number of events recorded at each stress level and ' $\mathrm{S}_{\mathrm{d}}$ ' represents the constant stress increment. ${ }^{8}$ The counted events represent either the failures or the survivals, depending on which has the smaller total. If survival or run out is the less frequent event, then the lowest stress level at which this occurs corresponds to the $\mathrm{i}=0$ level and $\mathrm{n}_{\mathrm{i}}$ corresponds to the number of specimens which survives stress level $i$. If failure is the less frequent event, then the lowest stress level at which a failure was observed is the $i=0$ level and $n_{i}$ corresponds to the number of specimens which failed at stress level i. One of the conditions of the Dixon and Mood theory is that the sample size should be in the order of 40-50 specimens in order to use large sample theory on which the analysis is based. Additional research by Brownlee et al. ${ }^{18}$ for the application of the Dixon and Mood theory to the mean endurance limit has shown that the method is reliable even in samples as small as 5-10. In this study, a sample size of 5 or 6 specimens is used for each specimen geometry. 


\section{B. Determination of the highly stressed volume $\mathbf{V}_{90 \%}$}

The highly stressed volume method was originally developed by Kuguel in $1960 .{ }^{23}$ The highly stressed volume is defined as the small volume which is subjected to more than $90 \%$ of the maximum stress occurring in the notch. Kuguel's equation shows a linear relationship between the logarithm of this critical volume and the logarithm of the local endurable stress amplitude. This power law is shown below for two specimens (0) and (1) with different notch geometries.

$$
\sigma_{\mathrm{a}(1)}=\sigma_{\mathrm{a}(0)} \times\left(\frac{\mathrm{V}_{90 \%(1)}}{\mathrm{V}_{90 \%(0)}}\right)^{\mathrm{m}} \quad \text { with } \quad \mathrm{m}<0
$$

Originally, the highly stressed volume of a notched specimen was estimated by R. Kuguel using a triangular approximation. ${ }^{23}$ The use of numerical finite element software enhances the accuracy of this method considerably. In this study, MSC Patran/Nastran software is used for a $2 \mathrm{D}$ simulation using quadratic triangular finite elements. First, a two dimensional FE-model is created using symmetrical boundary conditions to reduce the computational effort. A very fine mesh with element size ranging from $0.002 \mathrm{~mm}$ close to the notch, to $1 \mathrm{~mm}$ further away from the notch is applied and a linear static finite element analysis is performed. The maximum principle stress in the center of the elements is exported to Matlab together with the area and position of every element. After sorting these parameters, elements close to the clamping- or force acting area are removed and the maximum principal stress $\left(\sigma_{\max }\right)$ in the remaining elements is calculated. Then the summation is made of the areas of all elements that are subjected to a stress level between $0.9 \sigma_{\max }$ and $\sigma_{\max }$. To calculate the highly stressed volume $\left(\mathrm{V}_{90 \%}\right)$, this area is multiplied with the thickness of the specimen. The last step is to plot the elements which are subjected to $>0.9 \sigma_{\max }$ in order to verify their position.

\section{Determination of the critical distance $\mathbf{L}_{c}$}

The critical distance theory is based on the stress gradient near the notch root in correspondence with the theories of Neuber ${ }^{24}$, Peterson ${ }^{25}$ and Heywood ${ }^{26}$ to account for the notch effect. Based on LEFM theory, a critical distance $\mathrm{L}_{\mathrm{C}}$ is calculated using the stress intensity range $\left(\Delta \mathrm{K}_{\mathrm{th}}\right)$ and the plain specimen fatigue limit $\left(\Delta \sigma_{0}\right)$ as shown in eq. $7{ }^{27}$ Failure will occur when the maximum principal stress at a distance $\mathrm{Lc} / 2$ from the notch root is equal to $\sigma_{0}$.

$$
L_{C}=\frac{1}{\pi} \times\left(\frac{\Delta \mathrm{K}_{\mathrm{th}}}{\Delta \sigma_{0}}\right)^{2}=\frac{1}{\pi} \times\left(\frac{10 \mathrm{MPam} \mathrm{m}^{0.5}}{257.4 \mathrm{MPa}}\right)^{2}=0.48 \mathrm{~mm} \text { (7) }
$$

To determine $\Delta \mathrm{K}_{\mathrm{th}}$, crack propagation experiments were carried out on $8 \mathrm{CT}$ specimens with straight through notch according to the ASTM E647 standard, load ratio $\mathrm{R}=0.1$ and test frequency of $15 \mathrm{~Hz} .{ }^{15}$ For the production of these test samples, a bidirectional scanning strategy was used in combination with the optimal scan parameters as indicated in Table 1 . The plain specimen fatigue limit $\left(\Delta \sigma_{0}\right)$ was determined according to the method described in subsection A. Apart from this analytical method, $\mathrm{L}_{\mathrm{C}}$ can also be found using a graphical procedure as shown in Figure 4.

For the three different fatigue specimen geometries, the linear elastic FE-model was used to plot the maximum principle stresses along a line drawn from the root of the notch in a direction normal to the loading direction (z-direction in Figure 3). Using the linear-elastic material hypothesis, these three lines were then vertically shifted until the maximum values were equal to the local range of the respective endurance limits as determined in subsection A. The critical distance can then be found as the intersection between these three stress gradient curves. $^{27}$

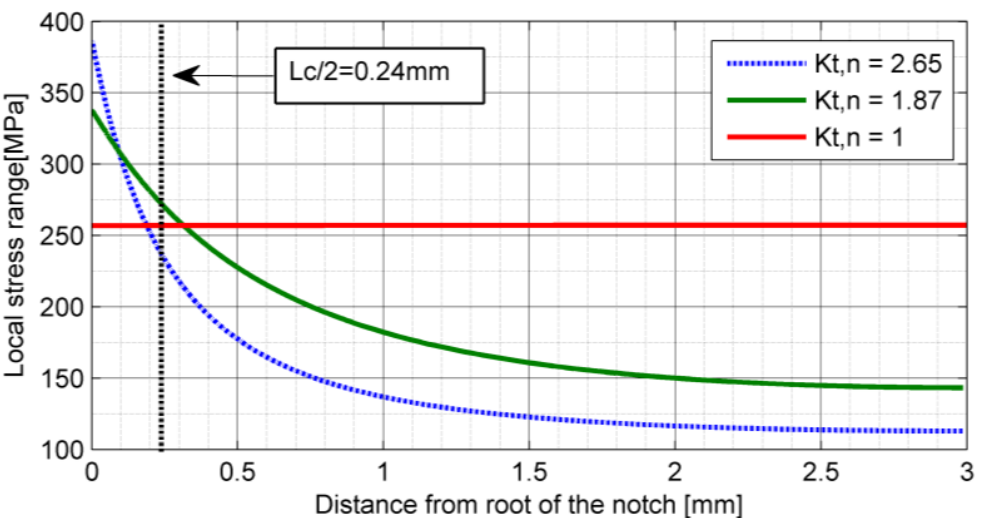

Figure 4. Stress gradients starting at the root of the notched specimens and scaled to the corresponding fatigue limits 


\section{Results and discussion}

Table 4 gives an overview of the results of this study. An important difference can be noticed between the analytical and numerical stress concentration factors $\mathrm{k}_{\mathrm{t}, \mathrm{a}}$ and $\mathrm{k}_{\mathrm{t}, \mathrm{n}}$. For post processing of the results, the more correct value of $\mathrm{k}_{\mathrm{t}, \mathrm{n}}$ was used. The elliptical curves used to account for the stair effect on the unnotched specimens leads to a very low $\mathrm{k}_{\mathrm{t}, \mathrm{n}}$ of 1.02 . This is crucial to avoid cracks initiating from the same points on the geometry.

Table 4. Fatigue results of the notched and unnotched specimens

\begin{tabular}{cccccccc}
\hline $\mathrm{k}_{\mathrm{t}, \mathrm{a}}$ & $\mathrm{k}_{\mathrm{t}, \mathrm{n}}$ & $\mathrm{M}_{\text {loc.a }}[\mathrm{MPa}]$ & $\mathrm{S}_{\mathrm{dev}, \text { loc.a }}[\mathrm{MPa}]$ & $\mathrm{M}_{\text {loc, }, \mathrm{MPa}}[\mathrm{MPa}$ & $\mathrm{M}_{\text {nom,a }}[\mathrm{MPa}]$ & $\mathrm{V}_{90 \%}\left[\mathrm{~mm}^{3}\right]$ & $\mathrm{V}_{90 \%}$ - elements \\
\hline 1 & 1.02 & 128.7 & 8.3 & 257.4 & 126.2 & 396.30 & 111583 \\
1.75 & 1.87 & 168.9 & 5.6 & 337.8 & 90.3 & 0.4524 & 8105 \\
2.5 & 2.65 & 193.2 & 7.2 & 386.4 & 72.9 & 0.0684 & 1937 \\
\hline
\end{tabular}

The results of the Dixon and Mood analysis show an acceptable standard deviation of the endurance limits. This is most likely due to the high relative densities, the accurate manufacturing of the notch, the heat treatment and the optimal scanning parameters of the SLM process. The fatigue data is presented in Figure 5. The fatigue resistance of SLM-Ti is substantially lower compared to the fatigue resistance of conventionally produced specimens subjected to the same loading conditions as documented in literature. Since the density of the SLM parts equals the density of the reference parts, the inferior fatigue properties are most likely caused by the anisotropy in the microstructure and not by the presence of pores or material imperfections. The fine acicular $\alpha$ '-martensite phase with sharp needles is more brittle than the globular microstructure of the reference material, leading to inferior resistance to material distortion. Furthermore, elongated grains are formed perpendicular to the loading direction of the specimens as shown in Figure 1C. This means that cracks can easily propagate along the grain boundaries.

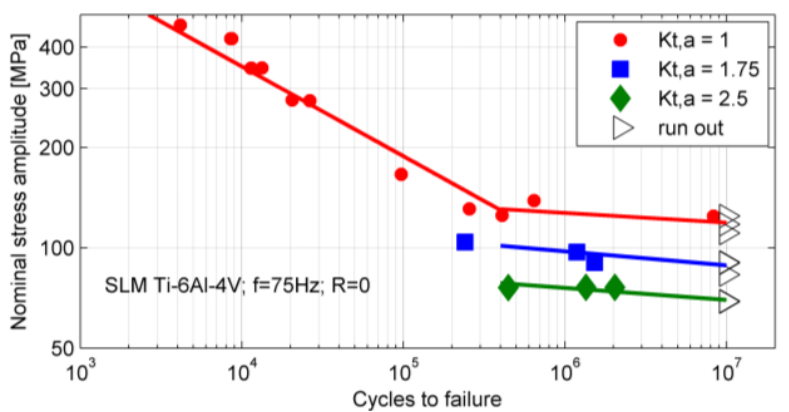

Figure 5. Wöhler curves of SLM-Ti6Al4V specimens

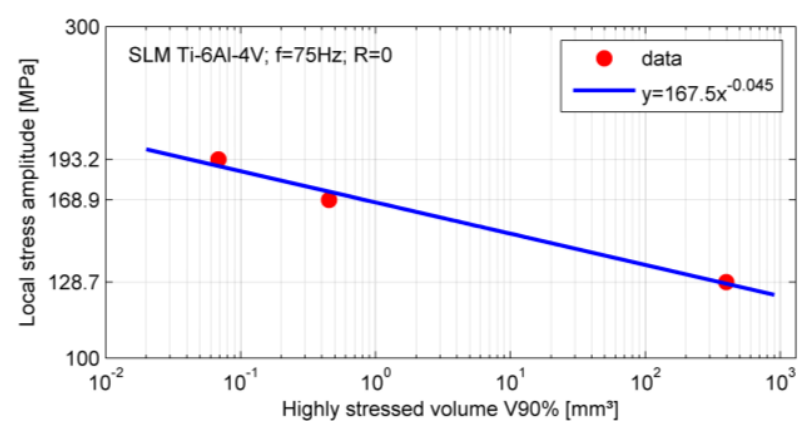

Figure 6. Local endurable stress amplitude as a function of the highly stressed volume

Table 4 also shows the large range of calculated highly stresses volumes. Finite element post processing indicates that a sufficient number of finite elements is used within the highly stressed volume to approximate the curvature of this volume with high accuracy. The relation between the mean values of the local endurable stress amplitudes and the corresponding highly stressed volumes can than be plotted on a double logarithmic scale as shown in Figure 6. The least square method is used to fit a power function of which the equation is indicated in the figure. It is clear that this data can be approximated as a straight line on the double logarithmic scale. Consequently, the presented results can be used for fatigue life estimations of notched SLM-Ti components and equation (6) can be successfully applied with $\mathrm{m}$ equal to -0.045 . Also the critical distance theory yields usefull results. The calculated critical distance of $0.48 \mathrm{~mm}$ corresponds to the value found by analyzing the scaled stress gradients for the three specimen geometries. Consequently, both the critical volume method and the critical distance theory can be used as efficient design tools for the fatigue life prediction over a wide range of stress concentration factors. 


\section{Conclusions}

In this paper, the critical distance theory and the highly stressed volume method are successfully adapted and used to account for the notch-effect in SLM-Ti6A14V specimens loaded in cyclic tension-compression. Using these techniques, the fatigue behavior of notched components in SLM-Ti6Al4V can be determined with a minimum amount of fatigue test specimens and straightforward finite element modeling. Consequently, the required time and effort for the experimental validation of numerical of analytical fatigue calculations can be condensed, leading to a more efficient and economically feasible design cycle.

Future work is needed to validate both theories using more specimens, different notch geometries and a variety of load cases. For this reason, a multi-axial fatigue test rig has been developed to apply combinations of bending and torsion to the cylindrical test specimens. ${ }^{28}$

\section{Acknowledgments}

This research is funded by a Ph.D grant of the Institute for the Promotion of Innovation through Science and Technology in Flanders (IWT-Vlaanderen). The author also gratefully acknowledges L. Thijs for detailed analysis of the microstructure and D. Vanbuel for his excellent master's thesis which formed the experimental groundwork for this research.

\section{References}

${ }^{1}$ J.P. Kruth, G. Levy, F. Klocke, T.H.C. Childs, Consolidation phenomena in laser and power-bed based layered manufacturing. Annals of CIRP. 2007, 56 (2).

${ }^{2} \mathrm{~L}$. Lü , J. Fuh, Laser-induced Materials and Processes for Rapid Prototyping, Kluwer, London, 2001.

${ }^{3}$ R. Noorani, Rapid Prototyping: Principles and Applications, Wiley, 2005.

${ }^{4}$ J.P. Kruth, M. Badrossamay, E. Yasa, J. Deckers, L. Thijs, J. Van Humbeeck, Part and material properties in selective laser melting of metals, 16th International Symposium on Electromachining, Shanghai, China, April, 2010.

${ }^{5}$ E. Yasa, J. Deckers, J.P. Kruth, M. Rombouts, J. Luyten, Experimental Investigation of Charpy Impact Tests on Metallic SLM parts. International Conference on Advanced Research in Virtual and Rapid Prototyping. 2009, pp. $207-214$.

${ }^{6}$ M. A. Lopez-Heredia, E. Goyenvalle, E. Aguado, P. Pilet, C. Leroux, M. Dorget, P. Weiss, P. Layrolle, Bone growth in rapid prototyped porous titanium implants, Journal of Biomedical Materials Research. 2008, Part A, Volume 85A, Issue 3, pp 664-673.

${ }^{7}$ I. Yadroitsev, L. Thivillon, Ph. Bertrand, I. Smurov, Strategy of manufacturing components with designed internal structure by selective laser melting of metallic powder. Applied Surface Science. 2007, 254, pp 980-983.

${ }^{8}$ K. Osakada, M. Shiomi, Flexible manufacturing of metallic products by selective laser melting of powder. International Journal of Machine Tools \& Manufacture. 2006, 46, pp 1188-1193.

${ }^{9}$ T. Gielis, M. Fleurinck, J. Bormans, B. Van Hooreweder, Development of a monoblock titanium steering wheel for a solar powered race vehicle using SLM. FISITA World Automotive Congress. Budapest, Hungary, 2010.

${ }^{10}$ L. Thijs, F. Verhaeghe, T. Craeghs, J. Van Humbeeck, J.P. Kruth, A study of the microstructural evolution during selective laser melting of Ti-6Al-4V. Acta Materialia. 2010, 58, pp 3303-3312.

${ }^{11}$ B. Van Hooreweder, F. De Coninck, D. Moens, R. Boonen, P. Sas, Microstructual characterization of SLS-PA12 specimens under dynamic tension/compression excitation. Polymer testing, 29, 2010, pp 319-326.

12 J. Van Vaerenbergh, Process optimisation in Selective Laser Melting, PhD. thesis, UTwente, 2008.

${ }^{13}$ FKM-guideline, Analytical Strength Assessment of Components in Mechanical Engineering, VDMA, 5th revised edition, 2003.

${ }^{14}$ E. Zahavi, V. Torbilo, Fatigue Design: Life Expectancy of Machine Parts. CRC press, 1996.

${ }^{15}$ B. Van Hooreweder, D. Moens, R. Boonen, J.P. Kruth, P. Sas, Analysis of Fracture Toughness and Crack Propagation of Ti6A14V Produced by Selective Laser Melting, Advanced Engineering Materials, 14, 2011, pp 92-97.

${ }^{16}$ Yao W., Xia K., Gu Y., On the fatigue notch factor Kf, Int. J. Fatigue, 17, 1995, pp 245-251.

${ }^{17}$ Dixon WJ, Mood AM., A method for obtaining and analyzing sensitivity data. J. Amer. Stat. Assoc. 43, 1948, pp 109-126.

${ }^{18}$ Brownlee, K.A., Hodges Jr., J.L., Rosenblatt, M., The up-and-down method with small samples, J. Amer. Stat. Assoc. 48, 1953, pp 262-277.

${ }^{19}$ Lin, S.K., Lee, Y.L., Evaluation of the staircase and the accelerated test methods for fatigue limit distributions, Int. J. Fatigue, 23, 2001, pp 75-83.

${ }^{20}$ R. Pollak, A. Palazotto, T. Nicholas. A simulation-based investigation of the staircase method for fatigue strength testing, Mechanics of Materials, 38, 2006, pp 1701-1181.

${ }^{21} \mathrm{~A}$. Buch, Fatigue data handbook, CRC press, 1998.

${ }^{22}$ H. E. Boyer, Atlas of fatigue curves, ASM International, 1986.

${ }^{23} \mathrm{R}$. Kuguel, The highly stressed volume of material as a fundamental parameter in the fatigue strength of metal members, T.A.M. report no. $169,1960$.

${ }^{24}$ H. Neuber, Theory of notch stresses: principles for exact stress calculation. Ann Arbor (MI): Edwards, 1946.

${ }^{25}$ R.E. Peterson, Notch sensitivity. Metal Fatigue. New York: McGraw-Hill; 1959, pp 293-306. 
${ }^{26}$ R.B. Heywood, Stress concentration factors, relation theoretical and practical factors in fatigue loading. Engineering, 1955, 179:146-8.

${ }^{27} \mathrm{D}$. Taylor, The theory of critical distances: a new perspective in fracture mechanics, Elsevier, UK, 2008.

${ }^{28}$ B. Van Hooreweder, D. Moens, R. Boonen, P. Sas. Design and Simulation of a novel Multi-axial Fatigue Test rig. Experimental Mechanics. DOI 10.1007/s11340-011-9510-3, 2011. 